\title{
Adherence to guidelines for management of chemotherapy-induced nausea and vomiting in a tertiary public hospital
}

\author{
Gustavo de Moura LÁZARO ${ }^{1}$ (D) , Juliane CARLOTTO ${ }^{1}$ (D) , Inajara ROTTA ${ }^{1}$ (D) \\ ${ }^{1}$ Complexo Hospital de Clínicas da Universidade Federal do Paraná \\ Corresponding author: ROTTA I, inarotta@gmail.com \\ Submitted: 28-04-2020 Resubmitted: 08-07-2020 Accepted: 15-07-2020 \\ Peer review: blind reviewer and Annemeri Livinallli
}

\begin{abstract}
Objectives: To assess if the antiemetic prophylaxis prescribed to patients exposed to chemotherapy is following the Antiemesis guideline published by the National Comprehensive Cancer Network (NCCN) version 3.2018. Methods: A medication review was performed, considering antiemetic's prescriptions of adult patients under treatment with moderate and high emetogenic potential antineoplastic agents, assisted on an outpatient basis in a tertiary public hospital, from May to September 2019. The information contained in the prescriptions was compared with the guideline recommendations in relation to the selection of the therapeutic class of the antiemetic, dose, route of administration, dosage regimen and duration of treatment, with the prophylaxis expected for the acute and delayed phases being evaluated. Results: Were included 87 patients, 38 and 49 of whom used chemotherapy drugs with high and moderate emetogenic potential, respectively. In the prescriptions containing highly emetogenic chemotherapeutic agents, the antiemetic therapy recommended for acute phase prophylaxis was incorrectly prescribed for 9 patients $(23.7 \%)$, and the problem encountered was dexamethasone underdose (16.7\%). In the delayed phase, problems were identified in the prescriptions of 35 patients (92.1\%), including the prescription of inappropriate medication (57.4\%), since the prescription contained ondansetron, not foreseen by the guideline at this stage, and the need for dexamethasone as an additional drug (18.5\%). For 22 patients (44.9\%) exposed to moderately emetogenic antineoplastic agents, the acute regimen was incorrectly prescribed, and the main problems identified were dexamethasone overdose (21.2\%) and the need for dexamethasone as an additional drug (5.0\%). Delayed antiemetic prophylaxis was incorrectly prescribed for 45 of them (91.8\%), with ondansetron treatment duration longer than recommended (26.2\%), need for dexamethasone or ondansetron as an additional medication $(23.7 \%)$ and therapeutic duplicity (12.5\%) the problems encountered. Conclusion: It is suggested the implementation of strategies aimed at increasing adherence to the guideline's recommendations by the prescribers, as well as access to medicines considered essential.
\end{abstract}

Keywords: nausea, vomiting, chemotherapy, clinical protocols.

\section{Adesão às diretrizes de manejo de náuseas e vômitos induzidos por quimioterapia em um hospital público terciário}

\begin{abstract}
Resumo
Objetivos: Avaliar se a profilaxia antiemética prescrita a pacientes expostos à quimioterapia está em conformidade com a diretriz Antiemesis publicada pela National Comprehensive Cancer Network (NCCN) versão 3.2018. Métodos: Foi realizada revisão da farmacoterapia, considerando as prescrições de antieméticos de pacientes adultos sob tratamento com antineoplásicos de moderado e alto potencial emetogênico, assistidos ambulatorialmente em um hospital público terciário, no período de maio a setembro de 2019. As informações constantes nas prescrições foram confrontadas com as recomendações da diretriz em relação à seleção da classe terapêutica do antiemético, dose, via de administração, regime posológico e tempo de tratamento, sendo avaliada a profilaxia prevista para as fases aguda e tardia. Resultados: Foram incluídos 87 pacientes, dos quais 38 e 49 utilizaram quimioterápicos de alto e moderado potencial emetogênico, respectivamente. Nas prescrições contendo quimioterápicos altamente emetogênicos, a terapia antiemética prevista para a profilaxia de fase aguda foi prescrita de forma incorreta para 9 pacientes $(23,7 \%)$, sendo o problema encontrado subdose de dexametasona (16,7\%). Na fase tardia, foram identificados problemas nas prescrições de 35 pacientes (92,1\%), incluindo prescrição de medicamento inadequado (57,4\%), uma vez que continham ondansetrona, não prevista pela diretriz nesta fase, e necessidade de dexametasona como medicamento adicional (18,5\%). Para 22 pacientes $(44,9 \%)$ expostos à quimioterapia de moderado potencial emetogênico, foi prescrito o esquema agudo de forma incorreta, sendo os principais problemas identificados prescrição de dexametasona em sobredose $(21,2 \%)$ e necessidade de dexametasona como medicamento adicional (5,0\%). Profilaxia antiemética tardia foi prescrita incorretamente para 45 deles (91,8\%), sendo duração superior do tratamento com ondansetrona (26,2\%), necessidade de dexametasona ou ondansetrona como medicamento adicional (23,7\%) e duplicidade terapêutica $(12,5 \%)$ os problemas encontrados. Conclusão: Sugere-se a implementação de estratégias voltadas ao aumento da adesão às recomendações das diretrizes pelos prescritores, assim como acesso aos medicamentos considerados essenciais.
\end{abstract}

Palavras-chave: náusea, vômito, quimioterapia, protocolos clínicos. 


\section{Introduction}

Chemotherapy treatment involves side effects that significantly affect patients' quality of life. Chemotherapy-induced nausea and vomiting (CINV) can lead to poor treatment adherence and to serious complications such as dehydration, nutrient depletion, metabolic imbalances, declining performance status, decreased functional capacity, bleeding, and esophageal wound. ${ }^{1,2}$ Its incidence and severity are related to the characteristics of the antineoplastic agent used, including its dose and potential to induce emesis, in addition to patient variables such as age, gender, history of alcohol abuse, reaction to the use of previous chemotherapy and anxiety. ${ }^{1,3}$

The emetogenic potential of the antineoplastic regimen is classified according to the associated probability of the constituent antineoplastics to induce emesis, being divided into minimum potential with a risk of less than $10 \%$, low potential with a risk of between $10 \%$ and $30 \%$, moderate potential with a risk of between $30 \%$ and $90 \%$ and high potential with probability $>90 \% .{ }^{1,3}$ However, it is estimated that when receiving adequate antiemetic prophylaxis prior to exposure to highly emetogenic chemotherapy, the percentage of patients with CINV can decrease to approximately $30 \%$, highlighting nausea is more difficult to control. ${ }^{4}$

CINV can manifest itself in the acute, late or even anticipatory phases. The acute phase comprises the first 24 hours of the day of chemotherapy administration, usually starting within 2 hours. The late phase, on the other hand, occurs up to 120 hours after a chemotherapy cycle, with an effective peak between 48 and 72 hours, and its appearance is associated with drugs of moderate to high emetogenic potential. ${ }^{5}$ Also, anticipatory emesis occurs a few days before the next chemotherapy cycle, especially in patients who experienced significant nausea and/or vomiting during previous cycles, with an incidence ranging from 18\% to $57 \%$. Adequate control during the first cycle of chemotherapy can decrease the occurrence of anticipatory emesis. ${ }^{1,5}$

The clinical practice guidelines published by the National Comprehensive Cancer Network (NCCN), ${ }^{1}$ the Multinational Association of Supportive Care in Cancer (MASCC) and the European Society of Medical Oncology (ESMO) ${ }^{3}$ and the American Society of Clinical Oncology $(\mathrm{ASCO})^{6}$ recommend antiemetic schemes containing a combination of dexamethasone and serotonin receptor antagonists $\left(5-\mathrm{HT}_{3}\right)$, including ondansetron, granisetrone or dolasetrone for the prophylaxis of CINV in patients receiving antineoplastic agents with moderate emetogenic potential. For those undergoing chemotherapy with high emetogenic potential, triple therapy with the addition of a neurokinin 1 (NK-1) receptor antagonist, such as aprepitant, rolapitant and fosaprepitant, and/or a quadruple regimen containing olanzapine, is recommended. ${ }^{1,3,6}$

The antiemetic regimen to be adopted must take into account the drug with the greatest emetogenic potential present in the chemotherapy protocol and the patient's specific risk factors. The NCCN guideline recommends that, on the day of administration (D1) of chemotherapy with high emetogenic potential, antiemetic prophylaxis should be used, containing a $5-\mathrm{HT}_{3}$ antagonist, dexamethasone and an NK-1 antagonist. For the late phase, treatment should be continued with dexamethasone on days 2 to 4 associated with aprepitant on days 2 to 3 , if used on the first day. For chemotherapeutics of moderate emetogenic potential, the $\mathrm{NCCN}$ recommends the use of a $5-\mathrm{HT}_{3}$ antagonist associated with dexamethasone on $\mathrm{D} 1$, followed by dexamethasone monotherapy or a $5-\mathrm{HT}_{3}$ antagonist on days 2 and 3 for late prophylaxis. Still, the use of lorazepam in patients at risk of nausea and/or anticipatory vomiting can be considered, being a useful adjuvant in reducing anxiety symptoms. ${ }^{1}$

A number of studies demonstrate the low adherence to the clinical protocols for the management of $\mathrm{CINV}^{7-10}$ however, there are few who consider this practice within the public health system. Thus, this study evaluated the prescription of antiemetic prophylaxis for outpatients exposed to moderate and high emetogenicity antineoplastic therapy compared to institutional recommendations, adapted from the NCCN guideline, version 3.2018.

\section{Methods}

This is a descriptive and observational study conducted in the Clinical Hospital Complex of the Federal University of Paraná. The study consisted of the analysis of prescriptions for antiemetics used in the prophylaxis of nausea and/or vomiting resulting from moderate and high emetogenic potential antineoplastic therapy.

Patients over 18 years of age, and who received outpatient treatment for solid tumors or hematological neoplasms, were included consecutively from May to September 2019. Only the first prescription of each patient in the period for a given therapeutic scheme was considered, regardless of the number of chemotherapy cycles performed. The research project was approved by the institution's Ethics Committee under CAAE No. 12019419.8.0000.0096.

To classify the antineoplastic protocol as having high or moderate emetogenic potential, the classification of the National Comprehensive Cancer Network (NCCN) ${ }^{1}$ was consulted, based on the medication in the case of monotherapy, and on the medication with the greatest emetogenic potential in the case of combined therapy.

To assess the conformity of the prescription of antiemetic therapy, NCCN version 3.2018, published in 2018, was considered, since the institutional protocols were defined by the medical team based on the recommendations of this guideline. In view of the unavailability of anti-emetics of the NK-1 antagonist class at the institution, provided for in all international guidelines for the highly emetogenic CINV prophylaxis, the protocols were adapted following the NCCN recommendation to increase the dose of dexamethasone to $20 \mathrm{mg}$ in acute phase prophylaxis. To assess adherence to the guideline, the parameters for selecting the therapeutic class of the antiemetic, dose, route of administration, dosing regimen and treatment time were considered, and the prophylaxis for the acute and late phases was evaluated.

The pharmacotherapy review performed was of type 1 , since only the information contained in the prescriptions was considered, without having direct contact with the patient. This pharmaceutical analysis of the prescription is common in a hospital setting and aims to identify medication errors. ${ }^{11,12}$ The classification of problems related to pharmacotherapy (PRPhs) involving selection and prescription defined by the Ministry of Health was used. For this purpose, the following problems were considered: prescription of inappropriate medication, being considered in cases in which medications not included in the guideline were prescribed; need for additional medication, being considered in cases of omission of medications recommended by the guideline; prescription in underdose or overdose; inadequate pharmaceutical form or route of administration; inadequate treatment duration; and therapeutic duplicity. ${ }^{13}$ 
Data was tabulated using the Excel 2016 software. The categorical variables were described by means of frequencies and percentages, and the continuous variables were presented as mean and standard deviation.

\section{Results}

In the study, 87 antiemetic prescriptions for moderate and high emetogenic potential prophylaxis issued to 87 patients were evaluated, since no patient was exposed to more than one chemotherapy protocol during the analysis period. As all the prescriptions were electronic, none was excluded due to lack of information.

Most of the patients were female (59.8\%) and the mean age was 54.4 years old (SD: 15.4). The most prevalent diagnoses were breast $(18.4 \%)$, colon (17.2\%), lymphoma (13.8\%), gynecological $(10.3 \%)$, and stomach $(9.2 \%)$ cancers. The most used antineoplastic therapy protocols included the combination of cisplatin and gemcitabine (11.5\%), carboplatin and paclitaxel (10.3\%), oxaliplatin, folinic acid and fluorouracil (FLOX; 10.3\%) and doxorubicin and cyclophosphamide (AC; 10.3\%). Prescription of moderate and high emetogenic potential protocols was found for $49(56.3 \%)$ and $38(43.7 \%)$ patients, respectively (Table 1).

The PRPhs identified in the prescriptions for antiemetic therapies are shown in Table 2, according to the emetogenic level of the protocols and to the phase of induction of nausea and/or vomiting symptoms. Regarding the high and moderate emetogenicity protocols, 9 PRPhs and 22 PRPhs were identified, respectively, for acute phase antiemetic therapy, and 45 PRPhs and 58 PRPhs, respectively, for the late phase.

In prescriptions containing highly emetogenic chemotherapeutic agents, the antiemetic therapy provided for acute phase prophylaxis was incorrectly prescribed for 9 patients (23.7\%), with the PRPh found being dexamethasone underdose, representing $16.7 \%(9 / 54)$ of the total PRPhs found in prescriptions with high emetogenic potential. For the late phase, problems were identified in the prescriptions of 35 patients (92.1\%), with the main PRPh found being inappropriate medication prescription (31/54; 57.4\%), as it is an institutionalized conduct to prescribe ondansetron, not provided for in the NCCN guideline for this phase, in order to compensate for the absence of the NK-1 receptor antagonist. Still in the late phase, it was verified that the need for dexamethasone as an additional medication was the second most frequent PRPh, corresponding to $18.5 \%(10 / 54)$ of the PRPhs found.

Antiemetic prophylaxis for chemotherapy of moderate emetogenic potential was prescribed in disagreement for 22 patients (44.9\%) in the acute phase and for 45 patients (91.8\%) in the late phase. For the acute phase, the main PRPh identified was the prescription of overdose dexamethasone (17/80; $21.2 \%)$, followed by the need for dexamethasone as an additional drug (4/80; 5.0\%), while for the late phase the identified PRPhs were longer duration of treatment with ondansetron (21/80; 26.2\%), need for dexamethasone or ondansetron as an additional drug $(19 / 80 ; 23.7 \%)$, as no antiemetic was prescribed, and therapeutic duplicity (10/80; 12.5\%), as ondansetron and dexamethasone were prescribed, and the NCCN guideline recommends the use of one class or another in the management of late emesis of patients using moderately emetogenic chemotherapeutic agents.
Table 1. Characteristics of the patients and of the treatments (Paraná, Brazil, 2019)

\begin{tabular}{lc}
\hline Variables & $\mathbf{n}(\%)$ \\
\hline Gender & \\
Female & $52(59.8)$ \\
Male & $35(40.2)$ \\
Age group & \\
19-29 years old & $6(6.9)$ \\
30-39 years old & $12(13.8)$ \\
40-49 years old & $11(12.6)$ \\
50-59 years old & $19(21.8)$ \\
60-69 years old & $27(31.0)$ \\
> 70 years old & $12(13.8)$ \\
Anti-neoplastic protocol & \\
Gemcitabine + Cisplatin & $10(11.5)$ \\
Carboplatin + Paclitaxel & $9(10.3)$ \\
FLOX & $9(10.3)$ \\
AC & $9(10.3)$ \\
FOLFOX & $5(5.7)$ \\
CAPOX & $5(5.7)$ \\
FOLFIRI & $5(5.7)$ \\
Cisplatin monotherapy & $5(5.7)$ \\
Others & $30(34.5)$ \\
Emetogenic level of the chemotherapy & \\
High & $38(43.7)$ \\
Moderate & $49(56.3)$ \\
Diagnosis & \\
Breast cancer & $16(18.4)$ \\
Colon cancer & $15(17.2)$ \\
Lymphomas & $12(13.8)$ \\
Gynecological cancer & $9(10.3)$ \\
Stomach cancer & $8(9.2)$ \\
Genitourinary cancer & $4(4.6)$ \\
Rectal cancer & $3(3.4)$ \\
Malignant neoplasm in connective and soft tissue & $3(3.4)$ \\
Esophageal cancer & $2(2.3)$ \\
Liver and biliary tract cancer & $2(2.3)$ \\
Pancreatic cancer & $2(2.3)$ \\
Lung cancer & $2(2.3)$ \\
Malignant neoplasm in bones and cartilages & $2(2.3)$ \\
Head, face and neck cancer & $2(2.3)$ \\
Others & $5(5.7)$ \\
\hline
\end{tabular}

LEGEND: The drugs which make up the protocols are the following: FLOX: oxaliplatin folinic acid, and fluorouracil; AC. doxorubicin and cyclophosphamide; FOLFOX: oxaliplatin, folinic acid, and fluorouracil, AC. doxOrubicin and cyclophosphamide, FOLFOX: oxaliplatin, , and fluorouracil; CAPOX: Oxaliplatin and capecitabine; FOLFIRI: irinotecan, folinic acid, and fluorouracil.

\section{Discussion}

In this study, low rates of adherence to the NCCN guideline were found, similar to what was reported by other authors who assessed agreement with the guidelines for prophylaxis of CINV. ${ }^{7-}$ 10 In the study by Beauchemin et al., although they included only young patients using antineoplastic agents of moderate and high emetogenic potential, only $36.1 \%$ of them received antiemetic therapy according to international guidelines. ${ }^{7}$ Nikbakht et al. also found a low rate of adherence to the guidelines, especially for the protocols of moderate and high emetogenicity. ${ }^{8}$ Bun et al. found agreement rates ranging from $21.5 \%$ to $52 \%$, depending on the degree of emetogenicity of the protocol in use and on the age range of the patients. The authors concluded that the risk 
Table 2. Problems related to the Pharmacotherapy involving selection and prescription (Paraná, Brazil, 2019)

\begin{tabular}{ll}
\hline Emetogenic potential & Total
\end{tabular}

\section{High emetogenic potential}

Acute prophylaxis

Late stage prophylaxis

Inappropriate medication prescription (ondansetron)

Need for additional medication (dexamethasone)

Overdose prescription (dexamethasone)

\section{Moderate emetogenic potential}

Acute prophylaxis

Overdose prescription (dexamethasone)

Late stage prophylaxis

Incorrect duration of treatment (ondansetron)

Need for additional medication (ondansetron or dexamethasone) of PRPhs was calculated in relation to the total of problems found for each emetogenic potential.

of errors in the antiemetic prescription is greater when it comes to prophylaxis for moderate and high emetogenic CINV, and of younger patients. ${ }^{9}$ Finally, França et al. identified low adherence (22\%) to the ASCO guideline in the prescriptions of antiemetics of patients exposed to chemotherapy of minimum, low, moderate, and high emetogenic potential in the setting of a Brazilian private hospital and, unlike other authors, found greater adherence in prescriptions containing highly emetogenic chemotherapy. ${ }^{10}$

The only PRPh identified in the prescriptions for prophylaxis of acute phase of protocols with high emetogenic potential was the prescription of dexamethasone in underdose (16.7\%). According to the NCCN guideline, the dose of dexamethasone should be reduced from $20 \mathrm{mg}$ to $12 \mathrm{mg}$ when associated with the NK-1 antagonist, since dexamethasone has its area under the curve (AUC) practically doubled, possibly due to the inhibition of CYP3A4. However, in the absence of an association, the guideline recommends that high doses of dexamethasone can be considered. ${ }^{1}$ Due to the lack of standardization of the NK-1 antagonist, the use of $20 \mathrm{mg}$ dexamethasone, administered intravenously or orally, is institutionalized for acute antiemetic prophylaxis of protocols with high emetogenic potential. Thus, doses of $12 \mathrm{mg}$ of dexamethasone were characterized as an underdose.

The recommendation to use NK-1 receptor antagonists for antiemetic prophylaxis in protocols with high emetogenic potential, both in the acute and late phases, is consolidated in the literature, and is also described in the $\mathrm{ASCO}^{6}$ and MASCC/ESMO ${ }^{3}$ guidelines. In the study by Chapell and Aapro, ${ }^{14}$ the use of aprepitant, an NK-1 antagonist, combined with a 5-HT antagonist and dexamethasone, led to statistically favorable results of complete response (absence of emesis and need for rescue therapy) regardless of the patient's age, when compared to regimens that did not include aprepitant. In another study conducted by the same author, ${ }^{15}$ patients with different types of tumor and treated with different chemotherapy regimens, receiving triple antiemetic therapy containing aprepitant, ondansetron and dexamethasone, presented statistically superior complete responses when compared to those patients who did not receive the NK-1 antagonist. Gralla et al. ${ }^{16}$ also demonstrated the benefit of adding aprepitant in the antiemetic therapy of patients exposed to highly emetogenic antineoplastic agents, when compared to patients who received only standard treatment. Although this study does not present data on the effectiveness of the antiemetic therapy, considering the significant increase in its effectiveness after the inclusion of NK-1 antagonists, described in the literature, it was suggested to discuss these and other evidences for the possible inclusion of these drugs in the list of selected medicines at the institution.

Although several antiemetic regimens have been shown to be effective, there is greater difficulty in controlling late symptoms, especially nausea. For chemotherapeutics with high emetogenic potential, the NCCN recommends the administration of dexamethasone at the dose of $8 \mathrm{mg}$ on days 2,3 , and 4 together with aprepitant at the dose of $80 \mathrm{mg}$ on days 2 and 3 , if this is used on D1. ${ }^{1}$ Although the exact mechanism of action is not fully understood, steroids play an important role in late antiemetic therapy. In this study, the main PRPh $(57.4 \%)$ in late prophylaxis of CINV for protocols with high emetogenic potential was the prescription of inappropriate medication (ondansetron). Ondansetron, granisetron, and dolasetron are effective in preventing acute CINV, but less effective for the late phase. A meta-analysis of randomized controlled clinical trials concluded that the addition of $5 \mathrm{HT}_{3}$ receptor antagonist drugs to the dexamethasone-containing regimen did not increase the 
antiemetic effect of corticosteroids in preventing the late stage of CINV. ${ }^{17}$ Latreille et al. also found that granisetron for prophylaxis of the late stage of CINV did not confer any additional benefit when compared to the use of isolated corticosteroids. ${ }^{18}$ Still, Smyth et al. reported that there was no significant difference in the control of late emesis between granisetron and placebo during days 2 to 4 after highly emetogenic chemotherapy (high dose of cisplatin). ${ }^{19}$ These findings are supported by a study that analyzed serotonin metabolism, involved in the physiological process of CINV, and demonstrated that the urinary peak of the serotonin metabolite (5-HIAA) occurs shortly after the infusion of chemotherapy, with no subsequent peaks. Thus, the study identified that the late stage of occurrence of CINV is not associated with the release of serotonin. ${ }^{20}$

According to the $\mathrm{NCCN}^{1}$ the incidence of emesis in patients receiving antineoplastic drugs with moderate emetogenic potential can vary from $30 \%$ to $90 \%$. In this context, for acute phase prophylaxis the NCCN recommends the combination of ondansetron in the dose of $8 \mathrm{mg}$ to $16 \mathrm{mg}$ with dexamethasone in the dose of $12 \mathrm{mg}$ administered intravenously. The Italian Group for Antiemetic Research ${ }^{21}$ demonstrated that doses of dexamethasone ranging from $8 \mathrm{mg}$ to $20 \mathrm{mg}$ showed similar complete prophylaxis, which led the authors to define the lowest dose, that is, $8 \mathrm{mg}$, as the standard dose, given its similar and greater efficacy safety, causing fewer side effects. In our study, the main PRPh found was the prescription of overdose dexamethasone (21.2\%). Prescribing high-dose antiemetics, in disagreement with the ASCO guideline, was the main PRPh found in another national study, corresponding to $44 \%$ of the total problems found. The authors emphasized that the use of excessive doses makes treatment more expensive and does not benefit symptom control. ${ }^{10}$

Protocols with moderate emetogenic potential are known to be associated with a significant incidence of late nausea and vomiting, justifying the use of antiemetics in this phase. ${ }^{3}$ In this study, the main PRPhs identified were longer duration of treatment with ondansetron (26.2\%), need for additional medication (23.7\%) when no antiemetics were prescribed, and therapeutic duplicity when both (dexamethasone and ondansetron) were prescribed (12.5\%). For late prophylaxis, on days 2 and 3 after chemotherapy the NCCN recommends the use of dexamethasone in a dose of $8 \mathrm{mg}$ daily or ondansetron in a dose of $8 \mathrm{mg}$ twice a day. ${ }^{1}$ Despite the lack of preference between the two drugs being described in this guideline, the MASCC/ESMO guideline recommends oral dexamethasone as the treatment of choice, and the ASCO guideline does not recommend ondansetron for late prophylaxis of CINV. ${ }^{3,6}$ Therefore, there seems to be no evidence in the literature to increase ondansetron treatment time to prevent these late symptoms. In addition, a randomized study conducted with 708 patients using protocols of moderate emetogenic potential concluded that the use of dexamethasone in combination with ondansetron did not lead to a statistically superior result when compared to the treatment with dexamethasone alone in the late phase, thus not justifying the use of combination therapy at this stage. ${ }^{22}$

Despite the innovations in the antiemetic treatment available, the incidence of CINV remains a problem that is difficult to control. The study by Ihbe-Heffinger et al. ${ }^{23}$ found that $32.8 \%$ of the patients receiving chemotherapy had one or more episodes of emesis in the acute phase, even though $89.2 \%$ had received adequate antiemetic therapy. Castro et al..$^{24}$ evaluated 42 women with breast cancer receiving highly emetogenic chemotherapy, and found that in the group of 20 women with adequate antiemetic therapy, 95\% experienced some symptoms of nausea and/or vomiting. In this context, it is important to highlight that other causes, such as the use of opioid analgesics and antibiotics, vestibular dysfunction, presence of metastases in the central nervous system, gastrointestinal obstruction, gastroparesis and other gastrointestinal comorbidities, anxiety, and additional treatment with radiotherapy, favor the onset of emesis and must be taken into account when defining the antiemetic regimen. ${ }^{1,25}$ After ruling out other potential causes of these symptoms, it must be ensured that the patient is receiving the appropriate therapy according to the emetogenic potential of the antineoplastic agent in use. When management is insufficient, consideration should be given to adjusting treatment to a regimen normally used for a group at higher risk. The addition of other agents or their replacement should be considered. ${ }^{25}$

As limitations of this study, the characteristics of the patient and the treatment were not considered in the prescription evaluation, such as disease staging, intention of chemotherapy, treatment phase, concomitant treatment with radiotherapy, and presence of comorbidities. Such aspects could justify clinical intentions to individualize antiemetic prophylaxis, not being a PRPh, such as option for combined therapy of antiemetics in the late phase of protocols of moderate emetogenic potential for refractory patients, or the absence/reduction of the dexamethasone dose in late antiemetic prophylaxis for patients with comorbidities that make the use of this drug inappropriate.

Despite the limitations, the study showed that non-adherence to the recommendations provided for in the international guidelines for CINV prophylaxis is high. These non-compliances can result in a higher incidence of nausea and/or vomiting, as reported in a study that evaluated antiemetic prescriptions from 8 European countries. ${ }^{26}$

\section{Conclusion}

The present study demonstrated the need for improvements in the prescription pattern of antiemetic prophylaxis, in order to prevent or minimize the occurrence of chemotherapy-induced nausea and/or vomiting. Strategies aimed at increasing adherence to the recommendations of the guidelines by the prescribers must be implemented, such as the use of computerized systems that guide the practice, as well as the standardization of drugs considered essential to the proper management of CINV, contributing to the improvement of the patient's quality of life.

\section{Funding sources}

Internship grant (Pharmacy - Area: Hematology/Oncology) from March 2018 to February 2020.

\section{Collaborators}

GML: conception, design, analysis, data interpretation, preparation of the article, and responsibility for all the information presented in the paper, ensuring accuracy and integrity of any its parts. JC: conception, analysis, data interpretation, guidance in the preparation, and critical review of the manuscript. IR: conception, analysis, data interpretation, guidance in the preparation, critical review of the manuscript, and final approval of the version to be published. 


\section{Acknowledgments}

To the Hospital Pharmacy Sector of the Clinical Hospital Complex of the Federal University of Paraná, and to the Multi-professional Internship Program, for their support in the development of this paper.

\section{Conflicts of interest statement}

The authors declare that there are no conflicts of interest regarding this article.

\section{References}

1. National Comprehensive Cancer Network (NCCN). Antiemesis. NCCN Clinical Practice Guidelines in Oncology. Version 3.2018, June 2018.

2. Aseeri M, Mukhtar A, Al Khansa S, et al. A retrospective review of antiemetic use for chemotherapy-induced nausea and vomiting in pediatric oncology patients at a tertiary care center. J Oncol Pharm Pract. 2013; 19(2):138-144.

3. Roila F, Molassiotis A, Herrstedt J, et al. 2016 MASCC and ESMO Guideline Update for the Prevention of ChemotherapyAnd Radiotherapy-Induced Nausea and Vomiting and of Nausea and Vomiting in Advanced Cancer Patients. Ann Oncol. 2016;27(5):119-133.

4. Herrstedt J. Antiemetics: an update and the MASCC guidelines applied in clinical practice. Nat Clin Pract Oncol. 2008;5(1):32-43.

5. Marsilio NR, Sampaio GC, Bueno D. Estudo piloto de utilização de medicamentos antieméticos em uma unidade de oncologia pediátrica. Rev. Bras. Farm. Hosp. Serv, São Paulo. 2014; 5 (1): 42-47.

6. Hesketh PJ, Kris MG, Basch E, et al. Antiemetics: American Society of Clinical Oncology Clinical Practice Guideline Update. J Clin Oncol. 2017;35(28):3240-3261.

7. Beauchemin $M$, Sung L, Hershman DL, et al. Guideline concordant care for prevention of acute chemotherapyinduced nausea and vomiting in children, adolescents, and young adults. Support Care Cancer. 2020 [epub ahead of print]

8. Nikbakht Z, Rajabi M, Shahrasbi A, et al. Evaluation of adherence to antiemetic treatment guidelines in patients with chemotherapy-induced nausea and vomiting in teaching hospitals in Tehran. J Cancer Educ. 2020 [epub ahead of print]

9. Bun S, Kunisawa S, Sasaki N, et al. Analysis of concordance with antiemetic guidelines in pediatric, adolescent, and young adult patients with cancer using a large-scale administrative database. Cancer Med. 2019; 8 (14):6243-6249.

10. França MS, Usón Junior PL, Antunes YP, et al. Assessment of adherence to the guidelines for the management of nausea and vomiting induced by chemotherapy. Einstein (São Paulo). 2015; 13 (2): 221-225.

11. Correr CJ, Otuki MF. Avaliação global da farmacoterapia. In: Cassyano Januário Correr; Michel Fleith Otuki. (Org.). A prática farmacêutica na farmácia comunitária. 1ed. Porto Alegre: Artmed, 2013, v. 1, p. 326-351.
12. Conselho Federal de Farmácia. Serviços farmacêuticos diretamente destinados ao paciente, à família e à comunidade: contextualização e arcabouço conceitual. 1. ed. Brasília: Conselho Federal de Farmácia, 2016. 200 p.

13. Brasil. Ministério da Saúde. Secretaria de Ciência, Tecnologia e Insumos Estratégicos. Departamento de Assistência Farmacêutica e Insumos Estratégicos. Cuidado Farmacêutico na Atenção Básica. Caderno 2: Capacitação para implantação dos serviços de clínica farmacêutica. Brasília: Ministério da Saúde, 2014. 308 p.

14. Chapell R, Aapro MS. Efficacy of aprepitant among patients aged 65 and over receiving moderately to highly emetogenic chemotherapy: a meta-analysis of unpublished data from previously published studies. J Geriatr Oncol. 2013; 4 (1):7883.

15. Aapro MS, Schmoll HJ, et al. Review of the efficacy of aprepitant for the prevention of chemotherapy-induced nausea and vomiting in a range of tumor types. Cancer Treat Rev. 2013; 39 (1):113-117.

16. Gralla RJ, Wit R, Herrstedt J, et al. Antiemetic efficacy of the neurokinin-1 antagonist, aprepitant, plus a 5HT3 antagonist and a corticosteroid in patients receiving anthracyclines or cyclophosphamide in addition to high-dose cisplatin. Cancer. 2005; 104 (4): 864-868, 2005.

17. Huang JQ, Zheng GF, Deuson R, et al. Do 5-hydroxytryptamine3 receptor antagonists (5-HT3) improve the antiemetic effect of dexamethasone for preventing delayed chemotherapyinduced nausea and vomiting (CINV)? A meta-analysis of randomized controlled trials. Journal of Clinical Oncology. 2004; 22:14 suppl, 6037-6037.

18. Latreille J, Pater J, Johnston D, et al. Use of dexamethasone and granisetron in the control of delayed emesis for patients who receive highly emetogenic chemotherapy. National Cancer Institute of Canada Clinical Trials Group. J Clin Oncol. 1998; $16(3): 1174-1178$

19. Smyth J. Delayed emesis after high-dose cisplatin - The residual problem. Proceedings of the Satellite Symposium to the XVII Congress of the European Society for Medical Oncology, Lyon, France. 1992; 24-26.

20. Jordan K, Schmoll HJ, Aapro MS. Comparative activity of antiemetic drugs. Crit Rev Oncol Hematol. 2007; 61 (2):162175 .

21. Italian Group for Antiemetic Research. Double-blind, dosefinding study of four intravenous doses of dexamethasone in the prevention of cisplatin-induced acute emesis. Italian Group for Antiemetic Research. J Clin Oncol. 1998; 16 (9): 2937-2942.

22. Italian Group for Antiemetic Research. Dexamethasone alone or in combination with ondansetron for the prevention of delayed nausea and vomiting induced by chemotherapy. N Engl J Med. 2000; 343 (21): 1554-1559.

23. Ihbe-Heffinger A, Ehlken B, Bernard R, et al. The impact of delayed chemotherapy induced nausea and vomiting on patients, health resource utilization and costs in German cancer centers. Ann Oncol. 2004;15(3):526-36.

24. Castro MC, De Araújo AS, Mendes TR, et al. Efetividade de antieméticos no controle da êmese induzida pela 
quimioterapia antineoplásica, em domicílio. Acta Paul Enferm. 2014; 27 (5): 412-418.

25. Einhorn LH, Rapoport B, Navari RM, et al. 2016 updated MASCC/ESMO consensus recommendations: prevention of nausea and vomiting following multiple-day chemotherapy, high-dose chemotherapy, and breakthrough nausea and vomiting. Support Care Cancer. 2016; 25(1):303-308.

26. Aapro $M$, Molassiotis $A$, Dicato $M$, et al. The effect of guideline-consistent antiemetic therapy on chemotherapyinduced nausea and vomiting (CINV): the Pan European Emesis Registry (PEER). Ann Oncol. 2012; 23 (8): 1986-1992. 